Bulletin of Pharmaceutical Sciences
Assiut University
Website: http://bpsa.journals.ekb.eg/
e-mail: bullpharm@aun.edu.eg

\title{
PHYTOCHEMICAL AND BIOLOGICAL STUDY OF CENTAUREA CINERARIA L. CULTIVATED IN SYRIA
}

\author{
R. Joujeh ${ }^{*}$ \\ Department of Plant Biology, Damascus University, Damascus, Syria
}

\begin{abstract}
In the current study, $C$. cineraria plant was subjected to chemical and biological study. The plant extract was screened for its phytochemical constituents, its quantitative content of phenolics, and its activity in scavenging free radical (DPPH). The plant was subjected to a biological study, which includes investigating the potential cytotoxic effect of the plant towards human erythrocytes membranes, and the ability of the plant to protect erythrocytes against oxidative hemolysis. The results indicated that the extract did not contain saponins. Our study also showed that the extract contains a good content of phenolics $(41.12 \pm 0.6) \mathrm{mg} G A E / g$, and has good DPPH radical scavenging activity (79.96\% \pm 1.14$)$. The results showed that the extract does not have a toxic effect on erythrocytes membranes, and it is highly effective in protecting the membranes from oxidative damage $\left(I C_{50}\right.$ value was $\left.408.86 \mu \mathrm{g} / \mathrm{ml}\right)$. We hope that future studies will focus on the pharmaceutical aspects of this plant, and will not be considered as ornamental plant only.
\end{abstract}

\section{INTRODUCTION}

Plants have been a great resource of medicinal products which are used for the treatment of several ailments ${ }^{1}$. The Asteraceae is one of the largest families of flowering plants $^{2}$, with $1600-1700$ genera and 24,00030,000 species $^{3}$. Plants of this family are widely spread in the tropics and warm temperate regions of South, South-East and East-Asia, Africa and central South America ${ }^{4}$. Centaurea L.is a large genus in the Asteraceae family, with over 500 species widespread across the world. Some species are cultivated for spice, as ornamental plants, and in gardens. Centaurea species produce a vast array of secondary metabolites belonging to different classes of bioactive compounds. The plant Centaurea cineraria is perennial herb. Stems up to $80 \mathrm{~cm}$, erect, rarely procumbent, with few branches above. Leaves more or less tomentose, rarely glabrescent; lower lyrate to 2 pinnatisect. Capitula solitary. Bracts broadly ovate; appendages usually dark brown, the apex acuminate, not spinose; fimbriae 0.5-2 $\mathrm{mm}$. Pappus as long as achene, rarely absent ${ }^{6}$.
- Taxonomical Position of Centaurea species ${ }^{7}$

- Kingdom: Plantae

- Phylum: Magnoliophyta (Flowering Plants)

- Class: Magnoliopsida (Dicotyledons)

- Subclass: Asteridae

- Superorder: Asteranae

- Order: Asterales

- Family: Asteraceae

- Subfamily: Carduoideae

- Tribe: Cynareae

- Subtribe: Centaureinae

- Genus: Centaurea

- Species: C. cineraria

In general, $C$. cineraria is known as ornamental plant, and only very few studies have gone into investigating its chemical content and biological activities. The current study includes a chemical investigation of $C$. cineraria plant to screen its phytochemical compounds, determine its quantitative content of phenolic compounds, and test its activity in scavenging free radical (DPPH), in addition to a biological study, which includes investigating 
the potential cytotoxic effect of the plant towards human erythrocytes membranes, and the ability of the plant to protect healthy human erythrocytes against $\mathrm{H}_{2} \mathrm{O}_{2}$ induced hemolysis.

\section{METHODOLOGY}

\section{Plant material}

C. cineraria seeds were purchased, and then cultivated within strictly defined environmental conditions. For this study, the aerial parts of the cultivated plant were collected, shade dried and powdered using mechanical grinder.

\section{Preparation of plant extract}

Aqueous methanolic extract (AqME) of $C$. cineraria dried aerial parts was prepared according to Falleh et al. ${ }^{8}$ with few modifications.

The powdered plant material (50 gm) was mixed with $250 \mathrm{ml}$ of aqueous methanol $70 \%$ in a bottle. The extraction procedure was carried out using ultrasonic bath with frequency of 15 kilohertz $(\mathrm{kHz})$. The bottle was put in a sonic bath for 15 min. After that, the extract was vacuum filtered, the filtrate was collected and the residual was extracted three times using the same method. The total filtrate was evaporated by using rotary evaporator under reduced pressure at $45^{\circ} \mathrm{C}$, and stored in a desiccator. Finally, the extraction yield was calculated by the formula:

Yield $\%=$

$\left(\frac{\text { weight of dry extract }}{\text { weight of dry powdered plant material }}\right) \times 100$

\section{Qualitative analysis of phytochemical components}

C. cineraria aerial parts subjected to qualitative tests in order to characterize several chemical groups using standard procedures (Phenols ${ }^{9}, \quad$ Flavonoids $^{10}$, Tannins $^{11}$, Carbohydrates $^{12}$, Saponins ${ }^{13}$ ). The symbols + and - denote present, and absent.

\section{Total phenolic content}

Total phenolic content of the AqME extract of $C$. cineraria was spectrophotometrically determined using Folin-Ciocalteu method, with Gallic acid as standard (published in our previous study ${ }^{14}$ ). The total phenolic content was reported as $\mathrm{mg}$ of gallic acid equivalent (GAE) per gram of dry extract ${ }^{15}$.

\section{Free radical scavenging activity (DPPH method)}

The free radical scavenging activity of the AqME extract was determined according to Rashed $^{16}$, with modifications. First, DPPH solution was prepared in ethanol with final concentration of $45 \mu \mathrm{g} / \mathrm{ml}$. Then, $1 \mathrm{ml}$ of each plant extract $(0.005 \mathrm{~g} / \mathrm{ml})$ was added to Freshly prepared $3 \mathrm{ml}$ of DPPH solution. After $30 \mathrm{~min}$, the absorbance was measured at $517 \mathrm{~nm}$. Control sample was prepared using distilled water instead of the plant extract. The percentage of inhibition was calculated by comparing the absorbance values of the control and test samples using the equation:

Free radical scavenging activity $(\%)=$

$$
\left[\frac{\left(A_{c}-A_{t}\right)}{A_{c}}\right] \times 100
$$

$A_{c}$ is the absorbance of the control.

$A_{t}$ is the absorbance of the test sample.

\section{Hemolysis assay}

C. cineraria AqME extract was tested for its cytotoxic effects on normal human erythrocytes. Five milliliters of blood from fifteen healthy donors - after their approval was collected in EDTA vials. Normal human erythrocytes suspension (10\%), and the concentrations of plant extract were prepared in phosphate buffered saline (PBS) solution, (pH 7.4). In sterile Eppendorf tubes, $(1 \mathrm{ml})$ of each concentration (100-500-1000- 2000-4000) $\mu \mathrm{g} / \mathrm{ml}$ of the prepared extract was added to (1 $\mathrm{ml}$ ) of erythrocytes suspension (isolated from the blood samples of ten healthy donors). The mixture was then incubated in a water bath at $37^{\circ} \mathrm{C}$ for $30 \mathrm{~min}$, then samples were centrifuged $(2500 \mathrm{rpm} / \mathrm{min})$ for $10 \mathrm{mins}$, and the amount of free hemoglobin was estimated by measuring the absorption of the supernatant using a Spectrophotometer at the wavelength $540 \mathrm{~nm}$.

In order to compare the results, a negative control sample containing (1 ml) of PBS and (1 $\mathrm{ml}$ ) of erythrocytes suspension, and a positive control sample containing $(1 \mathrm{ml})$ of distilled 
water and $(1 \mathrm{ml})$ of erythrocytes suspension were prepared ${ }^{17}$.

The percentage of hemolysis was calculated according to the following formula:

$$
\text { Hemoly sis } \%=\frac{\left(\mathrm{OD}_{\text {test }}-\mathrm{OD}_{\text {con- }-}\right)}{\left(\mathrm{OD}_{\text {con+ }}-\mathrm{OD}_{\text {con- }}\right)} \times 100
$$

$\mathrm{OD}_{\text {test }}$ optical density of test sample.

$\mathrm{OD}_{\text {con- }}$ optical density of negative control (PBS).

$\mathrm{OD}_{\text {cont }}$ optical density of positive control (distilled water).

\section{Assessment of anti-hemolytic activity (hemolysis induced by oxidative factor)}

The anti-hemolytic activity of $C$. cineraria AqME extract was determined by the spectrophotometric procedure. Five milliliters of blood from fifteen healthy donors -after their approval- was collected in EDTA vials. $(1 \mathrm{ml})$ of each concentration of the extract (100-500$1000-2000-4000) \mu \mathrm{g} / \mathrm{ml}$ was mixed with $(0.5$ $\mathrm{ml})$ of the erythrocytes suspension (10\%) in sterile Eppendorf tubes. The mixture was incubated at laboratory temperature $(5 \mathrm{~min})$, then $(0.5 \mathrm{ml})$ of hydrogen peroxide solution (prepared using PBS) was added to induce oxidative degradation of the membrane lipid (haemolysis). The mixture was incubated for 4 hrs at a temperature of $37^{\circ} \mathrm{C}$. Then samples were centrifuged at a speed of $2500 \mathrm{rpm}$ for 10 min.

In order to compare the results, a negative control sample containing $(1 \mathrm{ml})$ of a PBS solution and $(0.5 \mathrm{ml})$ of the healthy erythrocyte suspension, and $(0.5 \mathrm{ml})$ of hydrogen peroxide solution was prepared.

Note: The hydrogen peroxide concentration was chosen to be able to cause hemolysis at approximately $95 \%$ in the negative control sample.

The percentage of hemolysis was calculated by estimating the amount of liberated hemoglobin using the spectrophotometer at the wavelength of 540 $\mathrm{nm}^{18}$. Based on this, the ability of plant extracts to protect erythrocyte from oxidative hemolysis was calculated according to the following equations:

Hemoly sis $\%=\frac{\text { OD of sample }}{\text { OD of control }} \times 100$

Protection $\%=100-$ [hemolysis]

\section{Statistical analysis}

Results were presented as average \pm standard deviation using Microsoft Excel 2010. Statistical Package for Social Science (SPSS) was used to perform the statistical tests.

\section{RESULTS AND DISCUSSION}

\section{Characteristics and yield of the plant extract}

C. cineraria AqME extract was characterized by a brown color, bitter taste and a pleasant smell. The extraction yield was $12.64 \%$.

\section{Phytochemical screening}

The results of the qualitative chemical analysis showed that the extract contain bioactive compounds as carbohydrates, phenols, tannins, flavonoids, while it was found that it does not contain saponins.

The phytochemical analysis of plants is important and have commercial attention in pharmaceuticals companies and research institutions for the industrialization of the new drugs $^{19}$. The chemical compounds that have been found in $C$. cineraria AqME extract have important biological activities, which gives this species medical importance, in addition to its use as an ornamental plant in different countries of the world. No reference studies were found on the phytochemical analysis for this plant to discuss our results. Our study may be the first chemical and biological study of this plant.

\section{Total phenolic content}

Our results showed good phenolic content in $C$. cineraria AqME extract with (41.12 \pm 0.6$)$ mg GAE/g.

It should be noted here that the phenolic content in the plant species in general is affected by the different environmental conditions for each geographical area, in addition to the different time of collecting the plant samples, and the difference of the solvent used in preparing the plant extracts ${ }^{20}$.

\section{Free radical scavenging activity}

Hydrogen donating ability of $C$. cineraria extract was measured by using DPPH assay. The results were expressed in percentage of inhibition of DPPH. The extract showed good 
DPPH radical scavenging activity with (79.96\% \pm 1.14$)$.

When testing the free radical scavenging activity of $C$. cineraria extract. It showed good DPPH radical scavenging activity. The ability to scavenge free radicals is determined by a 2.2-Diphenyl-1-picrylhydrazyl (DPPH) test, which is a free radical with a dark purple color in methanol and ethanol solutions. This test is based on an evaluation of the ability of plant extracts to reduce DPPH, which is inferred by the conversion of purple color to yellow.

\section{Hemolytic effect}

Hemolytic assay experiment was designed to evaluate the effect of five different concentrations of $C$. cineraria extract on red blood cells. The results showed that there were no toxic effects of the extract towards the erythrocyte membranes, although there was an increased direct relationship between the concentrations used from the plant extracts and the measured absorbance values. The tested concentrations caused a slight hemolysis (less than $5 \%$ at the concentration $4000 \mu \mathrm{g} / \mathrm{ml}$ ) and this percentage is very weak when compared with the corresponding high concentration (table 1).

Table 1: The percentages of hemolytic effect by $C$. cineraria extract.

\begin{tabular}{|c|c|}
\hline $\begin{array}{c}\text { Concentration } \\
(\mu \mathrm{g} / \mathrm{ml})\end{array}$ & Hemolysis \% \\
\hline 100 & $0.26 \pm 0.4$ \\
\hline 500 & $0.49 \pm 0.4$ \\
\hline 1000 & $2.36^{*} \pm 0.6$ \\
\hline 2000 & $3.72^{*} \pm 1.2$ \\
\hline 4000 & $4.84^{*} \pm 0.9$ \\
\hline
\end{tabular}

All values are represented as mean $\pm \mathrm{SD}$.

${ }^{(*)}$ Significant differences at $(p<0.05)$.

Before developing pharmaceutical agents from natural sources, it is important to screen them for cytotoxicity, and hemolytic activity represents a good indicator of cytotoxicity toward healthy erythrocytes. Triterpene and steroid saponins, which are abundant in plant extracts, have hemolytic properties ${ }^{21}$. When conducting a qualitative phytochemical analysis of $C$. cineraria, it was found that the studied extract did not contain saponins, and the extract did not actually cause noticeable cytotoxic effects on erythrocytes' membranes.

\section{Anti-hemolytic activity against oxidative hemolysis}

In this test, the extract's ability to reduce the damage caused by oxidative stress in the erythrocyte membranes was evaluated. In general, the results indicated that the addition of the gradient concentrations of the $C$. cineraria extract resulted in the inhibition of oxidative hemolysis, which was stimulated invitro, and in a relationship proportional to the gradual increase in the concentrations used, as shown in (table 2). A significant decrease in the percentages of erythrocyte hemolysis was demonstrated at high concentrations (10004000) $\mu \mathrm{g} / \mathrm{ml}$, which indicates the effectiveness of the extract in inhibiting the action of the oxidizing agent $\left(\mathrm{H}_{2} \mathrm{O}_{2}\right)$. The $\mathrm{IC}_{50}$ value was $408.86 \mu \mathrm{g} / \mathrm{ml}$ (Fig. 1). This result is consistent with the result of the free radical scavenging test, which confirms the plant's activity in scavenging DPPH.

When comparing the results of the current study of the plant $C$. cineraria cultivated in Syria with a previous study $^{14}$, that we conducted on the plant $C$. iberica wild spread in Syria, it became clear to us the great similarity in the chemical and biological effectiveness of the two species, and this may support the classification of these two species within the same genus.

Table 2: The percentages of hemolysis and protection by $C$. cineraria extract against oxidative hemolysis.

\begin{tabular}{||c|c|c|c||}
\hline $\begin{array}{c}\text { Concentration } \\
(\mu \mathrm{g} / \mathrm{ml})\end{array}$ & $\begin{array}{c}\text { Hemolysis } \\
\%\end{array}$ & $\begin{array}{c}\text { Protection } \\
\%\end{array}$ & $\begin{array}{c}\mathrm{IC}_{50} \\
(\mu \mathrm{g} / \mathrm{ml})\end{array}$ \\
\cline { 1 - 3 } 100 & 83.64 & $16.36 \pm 2.6$ & \\
\cline { 1 - 3 } 500 & 49.91 & $50.09 \pm 1.2$ & \multirow{2}{*}{408.86} \\
\cline { 1 - 3 } 1000 & 18.44 & $81.56 \pm 3.1$ & \\
\cline { 1 - 3 } 2000 & 12.96 & $87.04 \pm 1.4$ & \\
\cline { 1 - 2 } 4000 & 5.54 & $94.46 \pm 1.5$ & \\
\hline
\end{tabular}

Protection values are represented as mean \pm SD. 


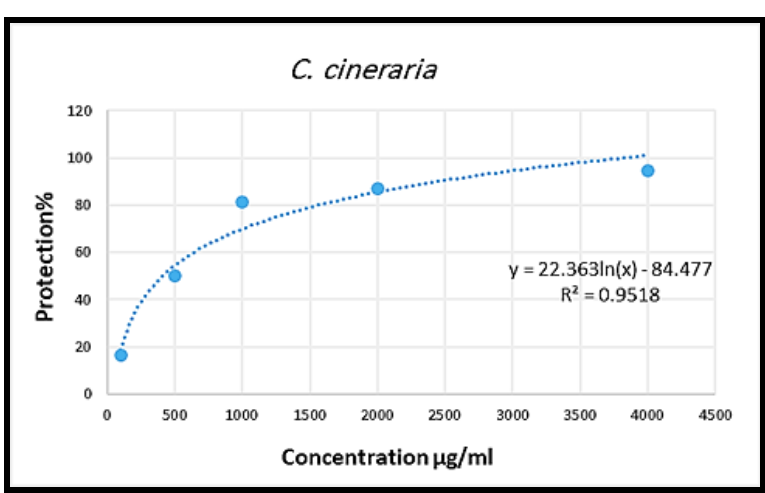

Fig 1: Anti-hemolytic activity of C. cineraria extracts against oxidative hemolysis.

\section{Conclusion}

In the light of the results obtained, we concluded that the aerial parts of $C$. cineraria, are very rich in phytochemical compounds, and has very low toxicity against human erythrocytes. The plant also has an antioxidant activity that is demonstrated by the ability of the extract to scavenge the free radical (DPPH), and protect normal human erythrocytes from oxidative damage induced by $\mathrm{H}_{2} \mathrm{O}_{2}$.

\section{Conflict of interest statement}

No conflict of interest.

\section{Acknowledgements}

The author is grateful to Research Laboratories of Pharmacognosy DepartmentPharmacy Faculty (University of Aleppo). The author thanks the researcher, Dima Joujeh for her assistance in revising the manuscript.

\section{REFERENCES}

1- I. Suntar, "The medicinal value of Asteraceae family plants in terms of wound healing activity", Fabad. J. Pharm. Sci., 39, 21-31 (2014).

2- M. Tadesse, "How to study the Asteraceae (Compositae) with special reference to the Asteraceae of fee", Ethiop. J. Biol. Sci., 13, 91-101 (2014).

3- A. Moreira-Muñoz and M. Muñoz-Schick, "Classification, diversity, and distribution of Chilean Asteraceae: Implications for biogeography and conservation", Diversity and Distribution, 13, 818-828 (2007).

4- A. H. M. Rahman, M. S. Alam, S. K. Khan, F. Ahmed, A. K. M. Rafiul Islam, et al., "Taxonomic studies on the family Asteraceae (Compositae) of the Rajshahi division", Res. J. Agric. \& Biol. Sci., 4 (2), 134-140 (2008).

5- O. Politeo, M. Skocibusic, I. Carev, F. Burcul, I. Jerkovic, M. Sarolic and M. Milos, "Phytochemical profiles of volatile constituents from Centaurea ragusina leaves and flowers and their antimicrobial effects", Nat. Product Commun., 7 (8), 1087-1090 (2012).

6- J. Dostal, J. G. In Tutin, V. H. Heywood, D. M. Moore, D. H. Valentine, S. M. Walters and D. A. Webb, "Flora Europaea", Cambridge Univ. Press, 1976, pp. 1-505.

7- A. Takhtajan, "Flowering Plants", Springer Science \& Business Media B.V, $2^{\text {nd }}$ Edn., 2009, p. 871.

8- H. Falleh, R. Ksouri, M. E. Lucchessi, Ch. Abdelly and Ch. Magné, "Ultrasoundassisted extraction: Effect of extraction time and solvent power on the levels of polyphenols and antioxidant activity of Mesembryanthemum edule L. Aizoaceae Shoots", Trop. J. Pharm. Res., 11 (2), 243-249 (2012).

9- G. Sangeetha and R. Vidhya, "In-vitro anti-inflammatory activity of different parts of Pedalium murex (L.)", Int. J. Herb. Med., 4 (3), 31-36 (2016).

10- P. Singh, R. Shrivastava, RC. Saxena, M. Sharma, M. S. Karchuli, et al., "Phytochemical screening and evaluation of antioxidant activity of Parkinsonia aculeate L. (Family-Leguminoseae) leaves extract", Int. J. Pharmtech. Res., 3 (4), 1952-1957 (2011).

11- A. Pandey and S. Tripathi, "Concept of standardization, extraction and pre phytochemical screening strategies for herbal drug", J. Pharmacogn. Phytochem., 2, 115-119 (2014).

12- R. M. Prabhavathi, M. P. Prasad and M. Jayaramu, "Studies on qualitative and quantitative phytochemical analysis of Cissus quadrangularis". Advances in Appl. Sci. Res., 7 (4), 11-17 (2016).

13- P. Tiwari, B. Kumar, M. Kaur, G. Kaur and H. Kaur, "Phytochemical screening and extraction: A review", Int. Pharm. Sci., 1 (1), 98-106 (2011). 
14- R. Joujeh, S. Zaid and S. Mona, "Phytochemical analysis, total phenolic content, hemolytic and antihemolytic activities of Centaurea iberica (Asteraceae)", Sci. J. King Faisal Univ. (Basic and Appl. Sci.), 35-43 (2019).

15- M. Alhafez, F. Kheder and M. Aljoubbeh, "Polyphenols, flavonoids and (-)epigallocatechin gallate in tea leaves and in their infusions under various conditions", Nutrition \& Food Sci., 44 (5), 455-463 (2014)

16- Kh. N. Rashed, "Antioxidant activity of different extracts of Vitex agnus-castus (L.) and phytochemical profile", Res. Pharm., 3 (6), 01-05 (2013).

17- M. Zohra and A. Fawzia, "Hemolytic activity of different herbal the extract used in Algeria", Int. J. Pharm. Sci. Res., 5, 495-500 (2014).
18- D. S. Joshan and S. Rawal, "Comparative evaluation of antioxidant and antihemolytic capacities of plants of Indian origin using multiple antioxidant assays", Int. J. Phytopharm., 2, 107-112 (2012).

19- A. Wadood, M. Ghufran, S. B. Jamal, M. Naeem, A. Khan, et al., "Phytochemical Analysis of medicinal plants occurring in local area of Mardan", Biochem. Anal. Biochem., 2 (4), 1-4 (2013).

20- E. Sariburun, S. Sahin, C. Demir, C. Turkben and V. Uylaser, "Phenolic content and antioxidant activity of raspberry and blackberry cultivars". $\boldsymbol{J}$. Food Sci., 75 (4), 328- 335 (2010).

21- Vo N. N. Quynh, E. O. Fukushima and T. Muranaka, "Structure and hemolytic activity relationships of triterpenoid saponins and sapogenins", J. Nat. Med., 71, 50-58 (2017). 


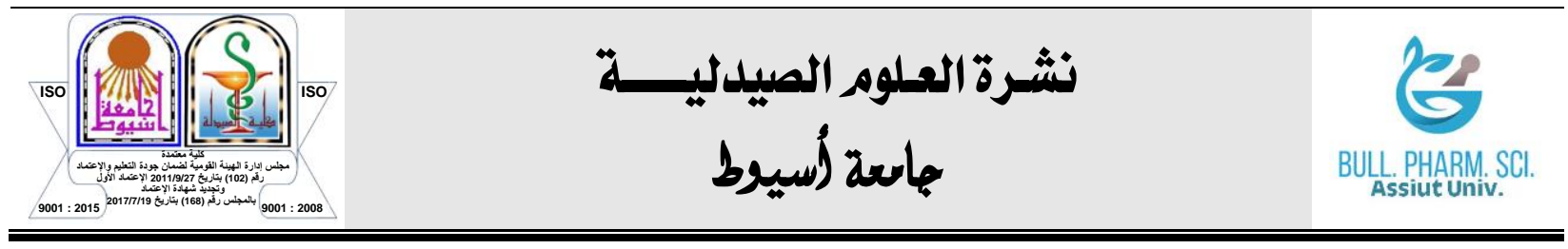

\section{Centaurea cineraria L. دراسة فيتوكيميائية وحيوية لنبات المزروع في سورية ربى جوجه}

قسم بيولوجيا النبات ، جامعة دمشق ، دمشق ، سوريا

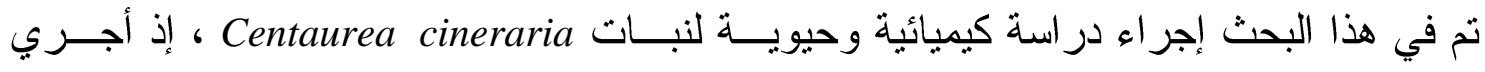
الكثف الكيميائي للتحري عن المكونات الكيميائية الرئيسة في المستخلص النبانية التياتي ، كما تم تحديد محتواه

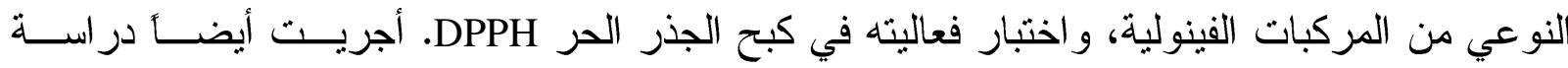

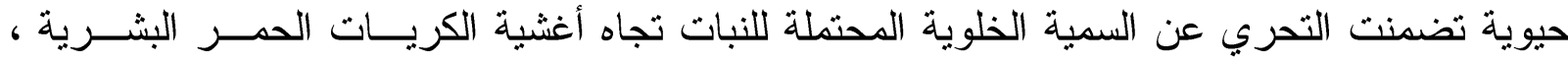

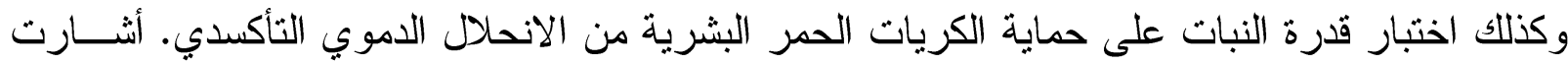

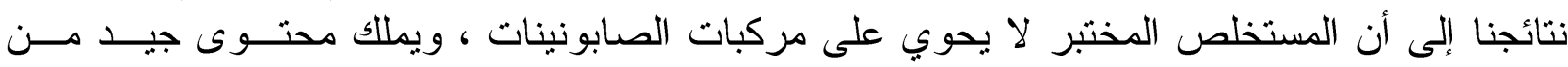

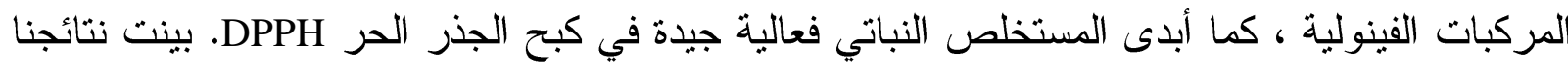

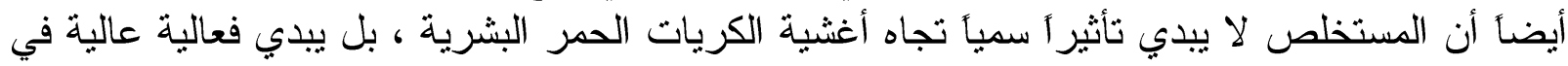

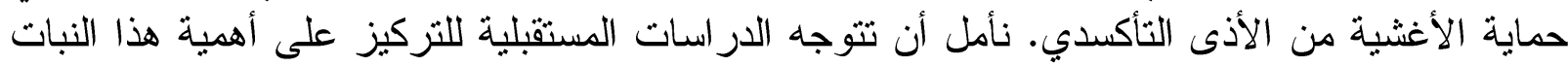

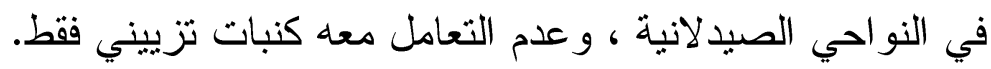

